\title{
Hazards Data Distribution System Update
}

When emergencies occur, first responders and disaster response teams need access to aerial photography and satellite imagery that is acquired within hours of the event. The U.S. Geological Survey (USGS) Hazards Data Distribution System (HDDS) provides quick and easy access to imagery and geospatial data that supports emergency response and recovery operations. HDDS provides data access and delivery services through graphic and (or) traditional directory-based interfaces that allow emergency response personnel to select and obtain pre-event baseline and post-event emergency response imagery.

The initial graphic user interface for the Hazard Data Distribution System, HDDS2, was released June 2010.

\section{HDDS2 features include:}

- Search by event

- Search by geographic coordinates

- Search by State and county

- Search by date

- Easily refinable search on results

- Map selection

- Access to all archived Emergency

- Operations event imagery

- RSS XML feeds for ingested data

- Item basket for data requests

- User feedback capability

\section{Additional functionality has recently been added to HDDS2.} These enhancements include:

- Registration Service

- Developed to assign and manage end-user roles and access based upon "event."

- Export of search results

- Provides the option to export KML, KMZ, and (or) shape files directly from the HDDS results page to the user system.

- Data ingest

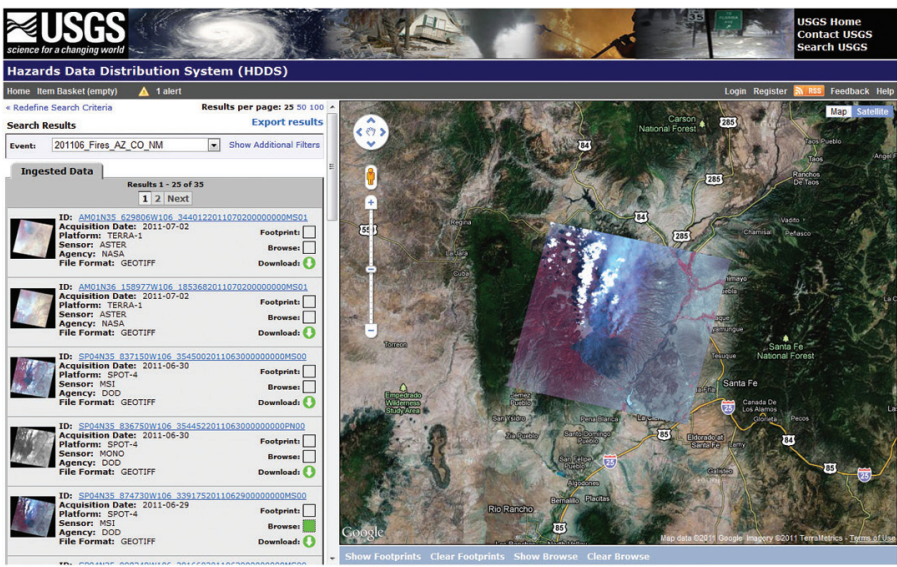

Figure 1. Screen capture of USGS Hazards Data Distribution System (HDDS) Web search results example:

http://hdds.usgs.gov/hdds2.

- Provides graphic search and visualization capability for several new datasets (IKONOS, EO-1 ALI/Hyperion, ASTER, and MODIS).

- Bulk data delivery

- Allows the user to manage multiple file and scene downloads at one time.

A user name and password are required to access the nonpublic services.

For more information, please contact Emergency Operations customer service by e-mailing eocustserv@usgs.gov, or contact:

Brenda K. Jones

USGS EROS Center

47914 252nd St

Sioux Falls, SD 57198

Telephone: 605-594-6503

Cell phone: 605-321-3995

E-mail:bkjones@usgs.gov

Rynn Lamb

USGS EROS Center

47914 252nd St

Sioux Falls, SD 57198

Telephone: 605-594-6958

Cell phone: 605-496-4925

E-mail: lamb@usgs.gov 